\title{
A SCHEME FOR THE EMPLOYMENT OF CONSUMPTIVES WHOSE DISEASE HAS BEEN ARRESTED.
}

\author{
By Miss HILDA JOSEPH.
}

(MEMBER.)

Notc.-It must be clearly understood that the scheme here put forward is given in the briefest possible form. Drainage, lighting, building, cost, etc., have been most carefully studied in detail, and the results arrived at would willingly be placed at the service of any who are interested in the scheme.

\footnotetext{
A GREAT deal has been written and said with regard to the alleged A failure of sanatorium treatment for the worling classes. It is an undeniable fact, and one well known to those engaged in the fight against tuberculosis, that a very large percentage of poor patients die within a few years of their treatment in sanatoria. The reason for the apparent failure usually given is that consumptive persons of the working classes rarely enter sanatoria sufficiently early in the course of their disease for a cure to be effected.

If an inquiry were carefully made with regard to all those persons who have left sanatoria with their disease arrested, it would be found that probably a large number of women who have husbands or fathers to support them, are doing well, but that a very small percentage of men retain their health, and are able to work for even a few years after treatment.

The reasons for the failure of the present system of after-care are, it seems :-

1. That in perhaps the majority of cases there is no help forthcoming for those who leave sanatoria.

2. That where help is attempted it is not sufficiently understood by those who undertake to find work and supervise these patients; that a residence of three-six months in a sanatorium cloes not, as a rule, effect
} 
a cure; that the lungs may be patched up, the disease arrested, and the general health greatly improved, but this is all. These people do not, as a rule, realise that the patient's constitution has to be built up afresl, that lie should have medical supervision for at least another year or two, and that he is totally unfit at first to do a full day's work.

3. The difficulty of finding any employment for consumptive patients is enormous. Rightly or wrongly there is a great fear in the lay mind of infection from those who lave passed through sanatoria. Then, too, the patient's former work is probably unsuitable for him, at any rate under the conditions in which it is usually carried on. His illness may have been larescly due to this. The difficulty of inducing a workman to take up some new form of employment can only be realised by those who have attempted it, and this difficulty is naturally much greater if the man has formerly been a skilled worker, making 30s. or even $£ 3$ a week, He may for a time take up another job, but sooner or later he usually drifts back to his old trade, or is forced to take to it again because he finds it impossible otherwise to make a living. These difficulties, too, are enormously increased in the case of consumptives, because here it is often necessary to induce men used to seclentary occupations to take up active work, and dwellers in towns to reside in the country.

\section{Buief Outhine of tile Scheme.}

Insufficient thought has been given to the after employment of consumptives, and from this cause much of the curative work, done at so great an expense and to which so much valuable time and effort is given, is thrown away. In the following parges an attempt is made to offer a solution of the difficulty. To those who have not thought over the matter carefully the ideal method would seem to be to put these patients to work upon the land: but, how of ten is this practicable? They cannot do heavy lifting or digging, for fear of starting hamorrlage, so that it is next to inpossible to place them as labourers, as gardeners, or as farmers, unless, indeed, they were formerly so employed, and so could obtain positions witls someone under them to do the heavy work.

Ruling out a farm colony, as a solution of the difficulty, might it not be possible to form a small experimental open air colony in the country, where the patients could be employed on the work at which they were engaged, before they were stricken duwn by tuberculosis? It is surely economical to make use, whenever possible, of knowledge and skill which has already been acquired. It goes without saying, that the work must be carried on under conditions as hrgienic as it is possible for sanitary and 
medical science to make them. It is not proposed to separate the colonists from their families. Healthy, open air life, by building up the constitution of the children, would prove a most effectual agent in the prevention of the spread of tuberculosis. Those who have visited the homes of phthisical patients, know well how much illness and how marked a predisposition to consumption are found among the children.

It is realised that many patients, especially those who can only work a portion of the day, and whose families are too young to contribute any appreciable amount to the family exchequer, would fail, at first, to be selfsupporting, but it is not proposed to subsidize the wage earners. No colonist would be accepted who had not someone to assist him in case of need. The great majority of working people, who make use of sanatoria, are only able to do so through the outside assistance which they receive, and where the weekly income proved insufficient to feed, clothe, and house the family in comfort, an appointed official of the colony would apply to the society or friend, who had guaranteed to make good any deficit.

The difficulty of obtaining good houses, pure water supply, and sanitary conditions in the country are great, therefore the colony system, which would supply these wants, appears the most advisable.

\section{LAND.}

Mr. Joseph Fels has most generously offered for the purposes of the colony a plot of land in Essex from 10 to 25 acres, at the nominal rental

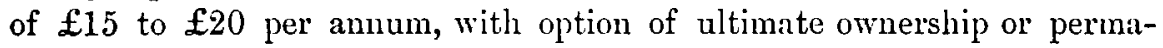
nent tenure. The site is high, and two miles from a railway station. The conditions imposed are: that a sufficient sum of money be raised to put the enterprise on a proper footing, and that the surplus land be cultivated by the colonists. It would be necessary to ascertain if the site so kindly offered is suitable for the purpose. Mr. Fels naturally desires to discuss the matter with those who may become responsible for the carrying out of the scheme.

\section{Employment of Colonists.}

As has been said above, the colony proposed is one in which the patients would principally be engaged on work with which they were familiar. As a large proportion of the consumptives of the East End of London are skilled workers at the tailoring trade, it seems wise to select this trade as the one with which to make our experiment. It has hitherto been prohibited as an employment for consumptives, but it should be possible to prove that it can be carried on under hygienic conditions.

Probably it would be found that the large majority of trades could be 
so carried on as to render them quite healthy for consumptives. Should a success be made with tailoring, one of the least hygienic, a distinct gain will have been made. The close and unhealthy atmosphere of the ordinary tailor's workshop, the stooping position of the workers, the heavy irons which must be lifted for pressing purposes, the steam, perhaps containing poisonous dyes, which must be inhaled, and the irregularity and seasonal character of the work, all make it at first sight appear unsuitable for the purpose. But these objections may be overcome. The factory would be built on most hygienic lines; it must be one room deep, with large windows the whole length of the room on both sides. The upper parts of the windows could be constructed so that they could be lowered into the room, to form, as it were, valves on what is known as the "hopper" plan; the lower should be French windows so that they can be opened in their entirety. In the very worst weather, the upper windows on one side of the room could be kept open. Very careful thought has been given to a scheme for carrying on the work in open-air sheds, but it appears to be impracticable. The stooping position of the workers is a serious objection, but conld be largely overcome by the use of power machines run by electricity; in this case the basting and finishing only would be done by hand. Daily exercise, which would be insisted upon, would do much to mitigate the bad effects of the sedentary occupation. With regard to pressing, seam pressing can be made suitable for the patients by the use of pressing-machine irous in which the weight of the iron in lifting is reduced by a lever. For final pressing it would be necessary to employ healthy men, as poisonous fumes containing dye may rise from the damp cloth which must be laid on the work. Gas irons are now used in up-to-date factories, and some are excellently constructed, so that the gas is entirely consumed. Tailoring is a season tracle, and is at all times irregular. If stock work only be undertaken this difficulty would be aroided, and it should be possible to keep the hands employed luring the slack season. Mantle-making could be undertaken as an additional trade, and would admirably suit the purpose of the colony, as mantle nakers are busy just when tailors proper are slack. It would be easy to take up the two branches. Several well-known firms who have heard of the proposed scheme have promised to supply tailoring work to the colonists, and their assistance would prove invaluable.

If the first experiment prove successful, factories might afterwards be erected for other trades. Printing and bootmaking have been suggested. With regard to the latter, the phthisical death rate amongst the workers is very high, and in this case great difficulties present themselves. Many of these could no doubt be overcome, but it would be impossible to entirely 
do away with the dust generited in the finishing process, and very expensive machinery is now required in a boot factory, so that the work could only be made to pay if undertaken on a very large scale.

Some of the patients and members of their families would probably. find employment about the colony as foremen, shop assistants, bakers, barbers, bootmakers, laundresses, dressmakers, milliners, etc. Whenever it was found practicable, the patients would be employed in light farming upon a model farm. Much of tine food for the colony might be grown, and egrgs, poultry and vegetables sent to market. Poultry farming might be made a speciality, as it would offer light and suitable work for the patients, and could be carried on as part of the general farm work. It would not be necessary to set apart land specially for it. This branch of farming is now recognised as lucrative if carefully managed, an important point in : scheme which must be made as self-supporting as possible. Bee-keepingr might also be unclertaken.

\section{Buthings otheir thax the Factory.}

It is obrious that if the families of the colonists are to accompany them to the colony model cottages must be erected. A farm-building, with a model cowhouse and dairy, are necessary for the carrying out of part of the scheme for the employment of the colonists. A general store and bakehouse might also be suggested, and a social institute, which might possibly form the upper story of the general store. The colonists would pay rent for their cottages, the percentage of interest which they would pay being fixed by those promoting the scheme. It would certainly be found that the cottages would exceed in cost the $£ 150$ cottages of the Cheap Cottages Exhibition recently held at Letchworth. In these no allowances had been made for the fees of builder or architect, and materials were charged at cost price; also the $£ 150$ did not include bath or other fittings, garden fencing, etc.

\section{Scriool.}

The school would be erected by the Local Educational Anthority if there were not sufficient accommodation for the children in the schools of the neighbourhood. The children might be given ordinary lessons for part of the day only, and during the remainder of school hours the boys could be taught farming and carpentry, the girls sewing, cooking, laundry work, dairy work and poultry farming. This idea if carried out would fit the pupils for country life, either at home or in the Colonies, and would do much to prevent them from drifting back into the large towns. In all 
probability it would be found that the Local Education Authority would approve of this scheme for the education of the children.

It may appear inadvisable that the children of consumptive parents should be thrown so much together, as childish companionship might possibly lead to marriage, but miny eminent physicians assure us that the children of such a union, reared under perfectly hygienic conditions, would probably be much stronger than those born of non-consumptive parents living in the East End of London.

\section{The Care of the Healti of the Residents.}

The services of a doctor, who should reside in the colony, or within easy reach of it, alpear to be indispensible. Each patient must be examined periodically, his exercise regulated, and the amount of work of which he is capable decided upon. The medical man should be in attendance each morning, and should see anyone who was not feeling well. He would afterwards be at liberty to practise outside the colony. He might be paid a retaining fee, to be supplemented by a small compulsory weekly payment collected with the rent from the colonists themselves.

\section{Social Recreation.}

The dulness of rural life has probably more to do with the exodus to the towns than any other single factor, and it would be essential that the social life of the colony should not be neglected. The proposed social institute might be made a centre of both recreation and instruction; class rooms would form part of it, where on week day evenings English, hygiene, carpentry, cooking, dressmaking, millinery, drilling, etc., might be taught. Such adjuncts as a billiard room, library, reading room, etc., readily suggest themselves. In the large hall debates, concerts, games and dances could take place, and if a stage were provided it should be possible to get amateurs from the nearest large towns to visit the colony and entertain the inmates.

\section{OFFICLALS.}

In addition to the doctor, who should preferably reside on the estate, such officials as a steward, a resident electrical engineer, and a lady superintendent seem necessary.

\section{The Cost.}

This is worked out in clet:il to amount to a total of $\$ 17,000$ for capital expenditure and a working expense, including interest on capital, of $£ 2,142$ per annum.

vol. xxvII. No. 10 . 
No estimate has been made for salaries paid to those employed in the factory, store or farm, as these would be deducted from the carnings of the different undertakings.

Would it be possible for the colony to earn $\mathfrak{2 , 1 4 2}$ a year?

To consider the tailoring manufactory first. It seems that for the first three to four years money must be lost over this. It would be impossible to make it pay its way with, say, 30 employés who were not working full time. The business could, however, be built up; and in five rears' time, if a hundred persons were employed, should make a substantial profit. The fact, however, must not be overlooked that male labour would almost entirely be employed, while other firms with which the factory would be in competition, largely employ females.

The store, if the charges were moderate, and the work of a good quality, should draw customers from the surrounding country. The institute would be supported by the members. The electric light should yield a profit, that is, at least, when the colony has become sufficiently large.

The cottages would be let at such rents as would pay a reasonable percentage on the capital invested, but it must be borne in mind that they would probably be quickly filled, and it would be necessary to build more, so that for some years a considerable sum of money must be put into the scheme to develop it.

It seems then that for at least five years no profit could be hoped for, but, on the contrary, more money would have to be put into the undertaking.

The working of the scheme would doubtless be difficult; some failures are inevitable, but there seems every hope that success would crown the effort. If these hopes are realised, the colony would form an object-lesson to be studied and imitated, possibly to be improved upon, by many countries which are now grappling with the great problem involved in the stamping out of consumption. Surely the day will come when no sinatorium will be opened, without some provision at the same time being made for the after employment of the patients.

Bailie Anpenson (Glasgow) said that, in his opinion, we were devoting too much attention to the (so-called) cure and after treatment of phithisis, and too little to its prevention. We should endeavour to improve the homes and the workplaces, and the babits and modes of life of the poor to a greater extent than we had hitherto, for therein lay the true cause of the mischief. 
Mr. W. H. W. Wulls (Newcastle-upon-Tyne) desired to make a few remarks in the way of extending a part of Mr. Bailie Anderson's speech, which, as a whole, was practically a negative answer to the paper. $\mathrm{Mr}$. Anderson said that one way of lessening the incidence and spread of consumption amongst workers was to prevent overcrowding in workshops. The speaker wished to remind the Conference that, on account of the provisions of the Factory and Workshop Act, overcrowding could not legally be prevented. When the Factory and Workshop Bill was before the country, copies of it were sent to all local authorities, and comments were inrited. $A$ mong many others, comments were sent in from the authority he had the honour to serve to the effect that, in providing 250 cubic teet of space per worker, a mininum floor space of 25 sq. feet should also be required. This advice was rejected, with the result that, where the workshop was very high, the total cubic space, divided by 250 , would often permit as many workers to occupy the room as could be packed close together when standing upright. This was no jest, but a very serious matter.

Mr. Peter Frfe (Glasgow) thought we should begin with prevention rather than with cure. We should endeavour to prevent phthisis by dealing with home and workplace in the tirst instance, rather than enlist public sympathy for hospitals, sanatoria, and after-employment colonies, the very existence of which would be unnecessary if poor people lived and worked under reasonably health! conditions.

Dn. Sconfierd (Sheffield) pleaded for fair consideration to be given to Miss Joseph's scheme for the employment of consumptives. There was too much of a tendency to meet proposals like this with platitudes, such as "Prevention is better than cure," and " what we ought to do is to see that our dwellings and worlsplaces are so constructed that they will not farour the development of consumption." When were we going to get these model dwellings and worliplaces for everybody? Not in the next hundred years. In the meantime, he believed in doing something to prevent the spread of infection.

Dr. Sydxey G. Vinter (Torpoint) had an objection to make to two points in Miss Joseph's paper. The first was that she proposed to employ these consumptives in the maling of clothing, and secondly, that consumptive children should attend ordinary schools. Both of these courses were, in his opinion, objectionable and dangerous.

Miss Jossipr replied, and insisted that the problem of consumption was a very large one, and needed tacliling at both ends. 